\title{
Fear of COVID-19 during confinement in Mauritius [version 1;
}

\section{peer review: 1 not approved]}

\author{
a survey-based study \\ Smita Goorah (D), Jayrani Cheeneebash, Ashvin Gopaul, Satish Ramchurn
}

University of Mauritius, Reduit, Mauritius

V1 First published: 10 Nov 2020, 2:64
https://doi.org/10.35241/emeraldopenres.13973.1
Latest published: 10 Nov 2020, 2:64

https://doi.org/10.35241/emeraldopenres.13973.1

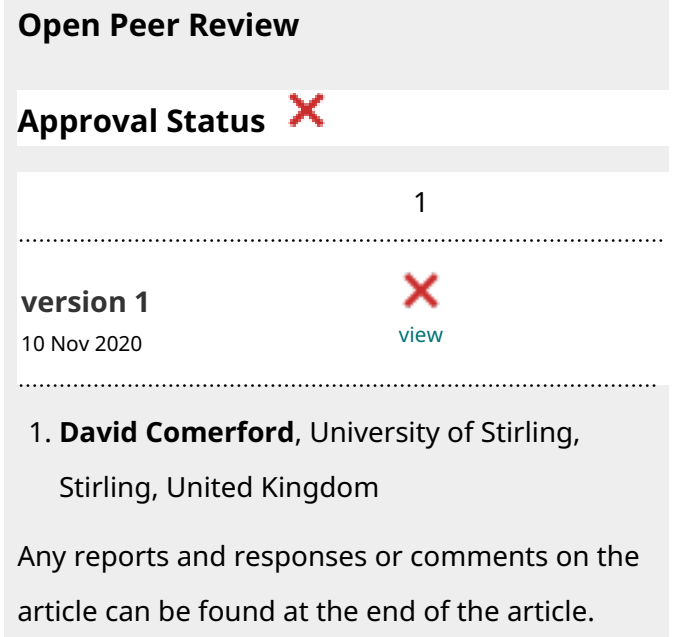

Methods: An anonymized online survey was carried out during confinement. Participation was voluntary. Participants reported fear level on a scale from 1-10, where no fear scored 1 and maximum fear scored 10. Participants reported the impact of news on their fear level on a scale of 1-10, where 1 represented no impact and 10 represented maximum impact. Participants reported the status of information received about COVID-19 on a scale of 1-10 where 1 represented no information on COVID-19 and 10 represented maximum information on COVID-19.

Results: The self-rated level of fear during confinement had a mean of 5.09 with $95 \%$ CI $[4.70,5.47]$. This increased to a mean of 6.39 with 95\% CI [6.00-6.78] at the prospect of confinement being lifted. The difference was statistically significant (paired-sample $T$-test, $\mathrm{p}<0.001$ ). With regard to the impact of news on fear of COVID-19, the mean for local news was 5.97 with $95 \%$ CI $[5.59,6.34]$ whereas that of worldwide news was 6.86 with $95 \%$ CI $[6.50,7.23]$. Worldwide news had a more significant impact (paired-sample $T$-test, $p<0.001$ ). The information score about COVID-19 had a mean of 5.12 with 95\%CI $[4.71,5.53]$.

Conclusions: Participants experienced a moderate level of fear of COVID-19 during confinement which increased at the prospect of confinement being lifted, implying that people felt safer during confinement. Their fear was influenced more by international news than by local news. Overall participants reported that they were 
moderately well informed about the COVID-19 pandemic.

\section{Keywords}

COVID-19, fear, confinement, pandemic, impact of news, Mauritius

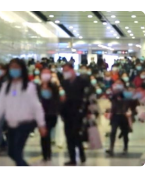

This article is included in the Coronavirus

(COVID-19) collection.

\section{Corresponding author: Smita Goorah (sm.goorah@uom.ac.mu)}

Author roles: Goorah S: Conceptualization, Data Curation, Formal Analysis, Investigation, Methodology, Project Administration, Supervision, Validation, Writing - Original Draft Preparation, Writing - Review \& Editing; Cheeneebash J: Data Curation, Formal Analysis, Investigation, Methodology, Writing - Original Draft Preparation, Writing - Review \& Editing; Gopaul A: Data Curation, Formal Analysis, Investigation, Methodology, Writing - Original Draft Preparation, Writing - Review \& Editing; Ramchurn S: Formal Analysis, Writing Original Draft Preparation, Writing - Review \& Editing

Competing interests: No competing interests were disclosed.

Grant information: The author(s) declared that no grants were involved in supporting this work.

Copyright: (c) 2020 Goorah S et al. This is an open access article distributed under the terms of the Creative Commons Attribution License, which permits unrestricted use, distribution, and reproduction in any medium, provided the original work is properly cited.

How to cite this article: Goorah S, Cheeneebash J, Gopaul A and Ramchurn S. Fear of COVID-19 during confinement in Mauritius [version 1; peer review: 1 not approved] Emerald Open Research 2020, 2:64 https://doi.org/10.35241/emeraldopenres.13973.1

First published: 10 Nov 2020, 2:64 https://doi.org/10.35241/emeraldopenres.13973.1 


\section{Introduction}

The first three cases of coronavirus disease 2019 (COVID19 ) in the island of Mauritius were officially diagnosed on $18^{\text {th }}$ March 2020. This disease is caused by the severe acute respiratory syndrome coronavirus 2 (SARS-CoV-2), and was declared a pandemic by the World Health Organization on $11^{\text {th }}$ March 2020 (Cucinotta \& Vanelli, 2020). COVID-19 first originated in the Hubei Province of China in December 2019 and has rapidly spread throughout the world (Guo et al., 2020). To date, as of $28^{\text {th }}$ September $2020,33,178,019$ cases and 998,784 deaths have been reported worldwide, with 367 cases and 10 deaths in Mauritius. The COVID-19 pandemic has received extensive press coverage globally, and analysis of news coverage regarding the globalization of the infection has shown a high level of media stress in the months of April and early May 2020.

Mauritius is a small tropical island of 1,222,268 inhabitants. It has extensive experience in successfully dealing with infectious diseases including outbreaks of malaria in the past (Tatarsky et al., 2011) and chikungunya fever (Ramchurn et al., 2008) and dengue fever (Ramchurn et al., 2009) in recent times. It has good surveillance and contact tracing systems. Moreover, Mauritius is regularly exposed to environmental risks and its population is experienced in coping with extreme climatic events such as cyclones and floods, thus demonstrating its resilience.

The authorities in Mauritius took stringent methods to combat the spread of COVID-19 in the island by imposing a sanitary lockdown as of 20th March 2020. This was followed by a complete lockdown on $24^{\text {th }}$ March 2020. There was easing of the lockdown on $15^{\text {th }}$ May 2020 and normal activities resumed on $1^{\text {st }}$ June 2020.

This was an unprecedented situation in Mauritius, and people have reacted diversely to the COVID-19 pandemic. Reports in social media have indicated significant levels of anxiety and fear in the population with respect to being infected by the virus. Other sources of anxiety and fear have related to travel restrictions, to being quarantined, to being confined and to being under lockdown. Social and economic factors have also contributed to fear. At the time of the present study, the population was under lockdown to contain the spread of the pandemic, and a return to normal life was being anticipated.

Pandemics are generally viewed with fear globally. An exploration of the literature shows us that human beings have had a historical inborn fear of death from infectious diseases and pandemics since ancient times (Riva et al., 2014). This deep fear also contributes to mental health sequelae in people and becomes entrenched for a long time in the collective memory of populations (Riva et al., 2014; Moukaddam, 2019).

In recent times, epidemics and pandemics have resulted in worldwide media coverage. The media can have a positive impact on the population by transmitting appropriate health-related information and thus contributing to public health efforts. On the other hand, its influence can be negative as it increases anxiety and alarm in people (Moukaddam, 2019).
In this study, our objective was to explore the level of fear of COVID-19 in the population during confinement in order to gain an understanding of people's reactions, as this may have health implications, thus influencing the health behavior of the population. However, the effects of collective fear in the population may also have far-reaching social and political repercussions beyond the immediate health impacts. Hence, an exploration of population fear levels was justified.

\section{Methods}

\section{Participants}

An anonymized online survey (Goorah et al., 2020b) was carried out from $29^{\text {th }}$ April 2020 to $5^{\text {th }}$ May 2020 during the period of strict confinement in Mauritius. This corresponded to day 43 and day 49 since the first diagnosed occurrence of COVID-19 in Mauritius and since confinement was started. A planned easing of the confinement had been scheduled for the $15^{\text {th }}$ May 2020 and normal activities were expected to resume on $1^{\text {st }}$ June 2020. Thus, the survey had been carried out before the scheduled easing of confinement.

The survey used the snowball sampling technique on electronic media, with participants being accessed via the WhatsApp mobile application. The researchers contacted colleagues and university students via WhatsApp and the survey was passed on. Any participant above 18 years of age who was willing to complete the survey was eligible to participate.

\section{Ethical considerations}

The research was carried out during a public health emergency in Mauritius at a time when there was strict confinement at home for the whole population. The only two ethics committees on the island were not operational at the time. We were guided by the World Health Organization (WHO) Ethical standards for research during public health emergencies. Although it was not possible to obtain formal ethics clearance during the confinement period, the study was carried out with all ethical guidelines being observed as stipulated by the WHO.

Participants were contacted via social media, which was the only way of recruiting participants, and they were asked to take part in a survey if they wished to do so. Completion of the survey was taken as consent to participate. Those who did not wish to participate in this research study did not complete the survey. Participation was therefore voluntary and was anonymous. All participants were above 18 years of age. We have an obligation to uphold internationally accepted ethical standards and we have done so to the best of our abilities while adapting to an exceptional situation.

\section{Survey}

The aim of the study was to assess the self-rated level of fear in participants during confinement and with respect to confinement being lifted. In addition, the impact of local and international news coverage on the level of fear was also investigated. Other variables gathered for this study included nationality, age, gender and education to ensure that our sampling was heterogeneous. The questionnaire used was a novel one devised and tested by us. No other validation was performed. The survey was a free online Google form. 
Regarding the fear level, participants were asked to report this on a scale from 1 to 10 where no fear scored 1 and the highest fear level scored 10.

The following two questions were used:

- How do you rate your level of fear during confinement?

- How do you feel about confinement being lifted?

The scores were categorized as follows: no fear level=1, low fear level $=2-4$, moderate fear level $=5-7$, high fear level=8-10.

Regarding the impact of news on the level of fear, participants were asked to report the impact of news on their level of fear on a scale from 1 to 10 where 1 represented no impact and 10 represented high impact.

The following two questions were used:

- How does the worldwide news impact on your fear of COVID-19?

- How does the local news impact on your fear of COVID-19?

The scores were categorized as follows: no impact $=1$, low impact $=2-4$, moderate impact $=5-7$, high impact $=8-10$.

Finally, participants were asked about how well informed they were about the COVID-19 disease on a scale of 1 to 10 .

The following question was used:

- Do you believe people are well informed about COVID-19?

The scores were categorized as follows: not informed $=1$, poorly informed $=2-4$, moderately informed $=5-7$, well informed $=8-10$.

\section{Data analysis}

Statistical analyses were performed using Microsoft Excel (2019). The characteristics of the participants were expressed in frequency and percentage. Means, standard deviations and $95 \%$ confidence intervals were calculated for each question of the survey. Paired-sample $T$-tests were done to study the differences in means.

\section{Results}

\section{Characteristics of the study sample}

176 participants took part in this study (Goorah et al., 2020a). The profile of the participants is shown in Table 1. The frequency of responses are shown in Figure 1 with most responses being received on the first day of the study. The results of the survey are described in Table 2.

The Cronbach's alpha value of the survey questionnaire was 0.711. This was within the acceptable range.

A paired-sample $T$-test was done to study the differences in the mean of fear experienced during confinement compared to the mean of fear experienced at the prospect of a lifting of confinement. The p-value was $<0.001$ showing that there was a significant difference and implying that people felt safer during confinement.

A paired-sample $T$-test was also done to study the impact of worldwide news compared to the impact of local news on the fear of COVID-19. The results showed that there was a significant difference at $\mathrm{p}<0.001$ with worldwide news having more impact on the perceived level of fear than local news.

The information score about COVID-19 had a mean of 5.12 with $95 \% \mathrm{CI}[4.71,5.53]$ showing that people felt that they were moderately well informed about the COVID-19 pandemic.

\section{Discussion}

Fear of the COVID-19 pandemic has been widespread throughout the world. This has included the fear of experiencing the direct effects of the COVID-19 disease itself, namely the fear of contracting the infectious disease and the fear of dying from it. This fear has been compounded by associated fears related to COVID-19 (Taylor et al., 2020) such as the fear of contaminated objects as well as fears relating to economic and social conditions, fears of food shortages, fears relating to travel and fear of foreigners. There is also a general fear of the unknown experienced by people who are exposed to the continuous media reporting on COVID-19, which is amplified by 24-hour news

\begin{tabular}{l|l|l|l|}
\hline \multicolumn{3}{l}{$\begin{array}{l}\text { Table 1. Characteristics of } \\
\text { participants. }\end{array}$} \\
\hline Variable & N & $\%$ \\
\hline Gender & Male & 69 & 39.2 \\
\hline & Female & 107 & 60.8 \\
\hline Age (years) & & & \\
\hline & $18-30$ & 78 & 44.3 \\
\hline & $31-40$ & 27 & 15.3 \\
\hline & $41-50$ & 29 & 16.5 \\
\hline & $51-65$ & 32 & 18.2 \\
\hline & $>65$ & 10 & 5.7 \\
\hline Education level & & \\
\hline & Primary & 0 & 0 \\
\hline & Secondary & 46 & 26.1 \\
\hline & Tertiary & 91 & 51.8 \\
\hline & Professional & 39 & 22.1 \\
\hline
\end{tabular}




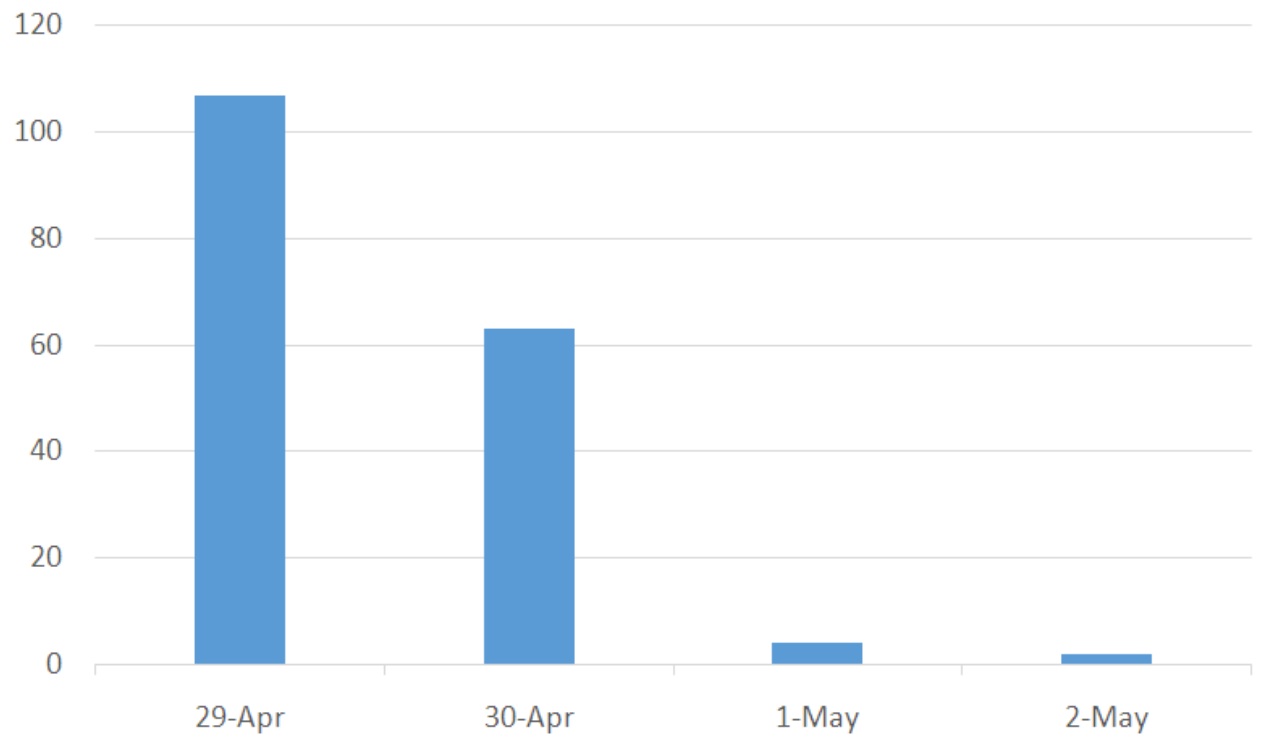

Figure 1. Frequency of responses over the duration of the survey.

\section{Table 2. Results of the survey.}

\begin{tabular}{|c|c|c|c|c|c|c|}
\hline Question & $\mathbf{N}$ & Min. & Max. & Mean & $\begin{array}{l}\text { Standard } \\
\text { deviation }\end{array}$ & $\begin{array}{l}95 \% \text { Confidence } \\
\text { Interval }\end{array}$ \\
\hline How do you rate your level of fear during confinement? & 176 & 1 & 10 & 5.09 & 2.58 & {$[4.70,5.47]$} \\
\hline How do you feel about confinement being lifted? & 176 & 1 & 10 & 6.39 & 2.64 & {$[6.00,6.78]$} \\
\hline How does the worldwide news impact on your fear of COVID-19? & 176 & 1 & 10 & 6.86 & 2.47 & {$[6.50,7.23]$} \\
\hline How does the local news impact on your fear of COVID-19? & 176 & 1 & 10 & 5.97 & 2.55 & {$[5.59,6.34]$} \\
\hline Do you believe people are well informed about COVID-19? & 176 & 1 & 10 & 5.12 & 2.76 & {$[4.71,5.53]$} \\
\hline
\end{tabular}

channels. In addition, fear of confinement at home has its own set of characteristics and needs to be investigated further. Moreover, this whole landscape of fear encompasses different levels of psychological distress and trauma, anxiety and stress (Qiu et al., 2020) and other subjective uncomfortable feelings which are difficult to assess objectively in the context of confinement.

In this study, we used a 10-point scale, which gave enough points to discriminate between responses. We assumed that the intervals between the scale values could be treated as equal, making it an interval scale for parametric statistics to be justified. The study would have yielded better results had we used validated questionnaires, particularly related to COVID-19 fears (Taylor et al., 2020). However, these were not available at the time of the study.

In this study, we explored the subjective fear that people experienced during confinement with respect to COVID-19 and how fearful they felt at the prospect of confinement being lifted. We found that participants had a mean self-reported fear level of 5.09 during confinement but this increased to 6.39 at the perspective of confinement being lifted. The difference was statistically significant indicating that participants were more fearful at the prospect of confinement being lifted. Thus, they felt safer during confinement.

Our study also showed that worldwide news had more impact than local news on the fear of COVID-19. Most Mauritian households have access to 24-hour international news channels via television and the internet as well as through radio and the press, and the COVID-19 pandemic throughout the world has resulted in extensive media coverage. It is important to note that participants felt that they were moderately well-informed about COVID-19 (mean score=5.12).

Although the different dimensions and causes of fear were not explored in detail, this study shows that there was a 
moderate component of fear towards COVID-19 in Mauritius during confinement, and that this fear was impacted more by worldwide news than by local news. The results must however be interpreted within the context of a small sample consisting mostly of young educated participants who were recruited through social media only. A larger and more comprehensive study was not possible during the confinement period. However, the data reflects the actual situation which was prevailing at the time of the study, and it would have been difficult to carry out such a study retrospectively. More research work is needed to investigate peoples' reactions to pandemics at the population level as these may have direct effects on health and health behavior, and also on society and politics.

\section{Data availability}

Underlying data

Dryad: Fear of COVID-19 during confinement in Mauritius: a survey-based study.

https://doi.org/10.5061/dryad.h70rxwdgv (Goorah et al., 2020a)
This project contains the following underlying data:

- AmendedUploadFearofCOVID19_Mauritius.xlsx

Data are available under the terms of the Creative Commons Zero "No rights reserved" data waiver (CC0 1.0 Public domain dedication).

\section{Extended data}

Zenodo: Fear of COVID-19 during confinement in Mauritius: a survey-based study. http://doi.org/10.5281/zenodo.4126940 (Goorah et al., 2020b)

This project contains the following extended data:

- Questionnaire_Covidfear.docx (questionnaire used for study)

Data are available under the terms of the Creative Commons Attribution 4.0 International license.
Cucinotta D, Vanelli M: WHO Declares COVID-19 a Pandemic. Acta Biomed. 2020; 91(1): 157-160.

PubMed Abstract | Publisher Full Text | Free Full Text

Goorah S, Cheeneebash J, Gopaul A, et al.: Fear of COVID-19 during confinement in Mauritius: a survey-based study. Dryad, Dataset. 2020a. http://www.doi.org/10.5061/dryad.h70rxwdgv

Goorah S, Cheeneebash J, Gopaul A, et al:: Fear of COVID-19 during confinement in Mauritius: a survey-based study. Zenodo. 2020b. http://www.doi.org/10.5281/zenodo.4126940

Guo YR, Cao QD, Hong ZS, et al: The origin, transmission and clinical therapies on coronavirus disease 2019 (COVID-19) outbreak - an update on the status. Mil Med Res. 2020; 7(1): 11.

PubMed Abstract | Publisher Full Text | Free Full Text

Moukaddam M: Fear, soutbreaks, and pandemics: lessons learned.

Psychiatry Times. 2019; 36(11).

Reference Source

Qiu J, Shen B, Zhao M, et al:: A nationwide survey of psychological distress

among chinese people in the COVID-19 epidemic: implications and policy recommendations. Gen Psychiatr. 2020; 33: e100213.

Publisher Full Text

Ramchurn SK, Goorah SSD, Mungla D, et al: A study of the 2006 chikungunya epidemic outbreak in Mauritius. Internet Journal of Medical Update. 2008; 1 :

11-21.

Publisher Full Text

Ramchurn SK, Moheeput K, Goorah S: An analysis of a short-lived outbreak of dengue fever in Mauritius. Euro Surveill. 2009; 14(34): 19314. PubMed Abstract | Publisher Full Text

Riva MA, Benedetti M, Cesana G: Pandemic fear and literature: observations from Jack London's The Scarlet Plague. Emerg Infect Dis. 2014; 20(10): 1753-7. PubMed Abstract | Publisher Full Text | Free Full Text

Tatarsky A, Aboobakar S, Cohen JM, et al.: Preventing the reintroduction of malaria in Mauritius: a programmatic and financial assessment. PLOS One 2011; 6(9): e23832.

PubMed Abstract | Publisher Full Text | Free Full Text

Taylor S, Landry CA, Paluszek MM, et al.: Development and initial validation of the COVID Stress Scales. J Anxiety Disord. 2020; 72: 102232.

PubMed Abstract | Publisher Full Text | Free Full Text 


\section{Open Peer Review}

\section{Current Peer Review Status:}

\section{Version 1}

Reviewer Report 20 September 2021

https://doi.org/10.21956/emeraldopenres.15058.r27714

(C) 2021 Comerford D. This is an open access peer review report distributed under the terms of the Creative Commons Attribution License, which permits unrestricted use, distribution, and reproduction in any medium, provided the original work is properly cited.

\section{David Comerford}

Division of Economics, University of Stirling, Stirling, United Kingdom

How are we to interpret these dependent measures? The scale was created for this specific survey about Covid-19. We have no reference point against which to compare it e.g. is fear of Covid higher than fear of the common cold / getting stung by a jellyfish? Is it lower than fear of cancer? Who knows. This study is not meaningful.

Also, use of the Cronbach's Alpha test is insufficiently justified. A Cronbach's alpha is intended to test whether a set of scale items load onto the same latent variable. The authors have given us insufficient justification from the previous literature and no empirical evidence that these three scale items theoretically or conceptually should measure the same underlying latent variable. One plausible explanation for the high alpha is that the three items share a common response scale and the alpha is picking up variation in how individual respondents use that response scale.

Is the work clearly and accurately presented and does it cite the current literature? Partly

Is the study design appropriate and is the work technically sound?

No

Are sufficient details of methods and analysis provided to allow replication by others? Partly

If applicable, is the statistical analysis and its interpretation appropriate? No

Are all the source data underlying the results available to ensure full reproducibility? Partly

Are the conclusions drawn adequately supported by the results? 
No

Is the argument information presented in such a way that it can be understood by a nonacademic audience?

No

Does the piece present solutions to actual real world challenges?

No

Is real-world evidence provided to support any conclusions made?

No

Could any solutions being offered be effectively implemented in practice?

No

Competing Interests: No competing interests were disclosed.

Reviewer Expertise: Survey design

I confirm that I have read this submission and believe that I have an appropriate level of expertise to state that I do not consider it to be of an acceptable scientific standard, for reasons outlined above. 